\title{
Pharmacokinetic Interaction between Nisoldipine and Repaglinide in Rats
}

\author{
In Choi ${ }^{1}$, Dong-Hyun Choi ${ }^{2}$, Cheul-Ho Yeum² and Jun-Shik Choi ${ }^{3, *}$ \\ ${ }^{1}$ Department of Pharmacy, Chosun University Hospital, Gwangju 501-759, \\ ${ }^{2}$ College of Medicine, ${ }^{3}$ College of Pharmacy, Chosun University, Gwangju 501-759, Republic of Korea
}

\begin{abstract}
The purpose of this study was to investigate the effects of nisoldipine on the pharmacokinetics of repaglinide in rats. The effect of nisoldipine on cytochrome P450 (CYP) 3A4 activity and P-glycoprotein (P-gp) were evaluated. The pharmacokinetic parameters of repaglinide were also determined in rats after oral $\left(0.5 \mathrm{mg} \cdot \mathrm{kg}^{-1}\right)$ and intravenous $\left(0.2 \mathrm{mg} \cdot \mathrm{kg}^{-1}\right)$ administration of repaglinide to rats without or with nisoldipine $\left(0.3\right.$ and $\left.1.0 \mathrm{mg} \cdot \mathrm{kg}^{-1}\right)$. Nisoldipine inhibited CYP3A4 enzyme activity with a $50 \%$ inhibition concentration of $5.5 \mu \mathrm{M}$. In addition, nisoldipine significantly enhanced the cellular accumulation of rhodamine-123 in MCF-7/ADR cells overexpressing P-gp. Compared to the oral control group, nisoldipine significantly increased the $A_{U} C_{0-\infty}$ and the $C_{\max }$ of repaglinide by $46.9 \%$ and $24.9 \%$, respectively. Nisoldipine also increased the absolute bioavailability (A.B.) of repaglinide by $47.0 \%$ compared to the oral control group. Moreover, the relative bioavailability (R.B.) of repaglinide was 1.16- to 1.47-fold greater than that of the control group. Nisoldipine enhanced the oral bioavailability of repaglinide, which may be attributable to the inhibition of the CYP3A4-mediated metabolism in the small intestine and/or in the liver and to inhibition of P-gp in the small intestine rather than to reduction of renal elimination of repaglinide by nisoldipine. The increase in the oral bioavailability of repaglinide should be taken into consideration of potential drug interactions when co-administering repaglinide and nisoldipine.
\end{abstract}

Key Words: Repaglinide, Pharmacokinetics, Nisoldipine, P-gp, CYP3A4, Rat

\section{INTRODUCTION}

Type 2 diabetes mellitus is a complex heterogeneous metabolic disorder in which peripheral insulin resistance and impaired insulin release are the main pathogenetic factors (ElHoussieny et al., 2010). Repaglinide is a new carboxymethyl benzoic acid derivative, also known as 2-ethoxy-4-[2-[[3methyl-1-[2-(1-piperidinyl) phenyl] butyl] amino]- 2-exoethyl] benzoic acid (El-Houssieny et al., 2010). It is a novel post prandial glucose regulator for the treatment of type 2 diabetes mellitus (Hatorp et al., 1999; Marbury et al., 2000). Repaglinide is rapidly absorbed from the gastrointestinal tract after oral administration. It differs from other antidiabetic agents in its structure, binding profile, duration of action and mode of excretion (Culy and Jarvis, 2001). Repaglinide is primarily metabolized via oxidative biotransformation involving the hepatic microsomal cytochrome P450 system, particularly the CYP3A4 isoform (Bidstrup et al., 2003). The metabolic pathway of repaglinide indicates two major sites for the principal biotransformation of repaglinide: the piperidine ring and the aromatic carboxylic acid group (Bauer et al., 1997). Repa-

www.biomolther.org

Open Access http://dx.doi.org/10.4062/biomolther.2011.19.4.498

pISSN: 1976-9148 elSSN: 2005-4483

Copyright $\odot 2011$ The Korean Society of Applied Pharmacology glinide has affinity for P-gp and it can significantly contribute to potential drug-drug interactions with other P-gp substrates or inhibitors (Chang et al., 2006). Kajosaari et al. reported that co-administration of repaglinide with the known P-gp inhibitor cyclosporine A could significantly increase the plasma concentrations of repaglinide in humans (Kajosaari et al., 2005).

Nisoldipine is a calcium antagonist of the 1,4-dihydropyridine class, it is often clinically used as an anti-angina and vasodilating agent (Chandler et al., 1992). Nisoldipine is well absorbed from the gastrointestinal tract after oral administration, but undergoes rapid and extensive first-pass metabolism in the gut wall and liver (van Harten et al., 1989). Nisoldipine is mainly eliminated by metabolism. Oxidation of 1,4-dihydropyridine (nisoldipine) to pyridine, catalysed by CYP3A4, is the major metabolic route (Guengerich et al., 1991). In general, the substrate and/or inhibitors of CYP3A4 and P-gp overlap with each other (Wacher et al., 1995), however, there are few reports about P-gp activity for nisoldipine. Therefore, we evaluated the P-gp activity of nisoldipine using rhodamine-123 retention assays in P-gp-overexpressing MCF-7/ADR cells. In order to verification the inhibition of CYP enzyme activity, we

Received Aug 1, 2011 Revised Sep 16, 2011 Accepted Sep 19, 2011

*Corresponding Author

E-mail: jsachoi@chosun.ac.kr

Tel: +82-62-230-6365, Fax: +82-62-222-5414 
studied the CYP inhibition assay.

In general, the hypertension can be induced by the complications of diabetes. So, it is possible that clinically repaglinide, antidiabetic agent and nisoldipine, antihypertensive agent, can be prescribed for treatment of diabetes and hypertension (or cardiovascular disease) as a complications of diabetes. However, pharmacokinetic interaction between repaglinide and nisoldipine has not been reported in vivo. Therefore, the present study aims to investigate the effect of nisoldipine on CYP3A4 activity, P-gp activity and the pharmacokinetics of repaglinide after oral and intravenous administration in rats.

\section{MATERIALS AND METHODS}

\section{Materials}

Repaglinide and indomethacin (internal standard) were purchased from the Sigma-Aldrich Co. (St. Louis, MO, USA). Nisoldipine was purchased from the Hyundai Pharm Co. (Gangnam-gu, Seoul, Korea). HPLC-grade methanol and acetonitrile were acquired from Merck Co. (Darmstadt, Germany). All other chemicals for this study were of reagent grade and were used without further purification. Apparatus used in this study included an HPLC equipped with a Waters 1515 isocratic HPLC Pump, a Waters 717 plus auto sampler and a Waters $^{\mathrm{TM}} 2487$ scanning UV detector (Waters Co., Milford, MA, USA), an HPLC column temperature controller (Phenomenex Inc., CA, USA), a Bransonic ${ }^{\circledR}$ Ultrasonic Cleaner (Branson Ultrasonic Co., Danbury, CT, USA), a vortex-mixer (Scientific Industries Co., NY, USA), and a high-speed microcentrifuge (Hitachi Co., Tokyo, Japan).

\section{Animal experiments}

Male Sprague-Dawley rats (weighing 270-300 g) were purchased from the Dae Han Laboratory Animal Research Co. (Choongbuk, Korea) and were given access to a commercial rat chow diet (No. 322-7-1, Superfeed Co., Gangwon, Korea) and tap water. The animals were housed, two per cage, and maintained at $22 \pm 2{ }^{\circ} \mathrm{C}$ and $50-60 \%$ relative humidity under a 12:12 h light-dark cycle. The experiments were initiated after acclimation under these conditions for at least 1 week. The Animal Care Committee of Chosun University (Gwangju, Korea) approved the design and the conduct of this study. The rats were fasted for at least $24 \mathrm{~h}$ prior to the experiments and each animal was anaesthetized lightly with ether. The left femoral artery and vein were cannulated using polyethylene tubing (SP45, i.d. $0.58 \mathrm{~mm}$, o.d. $0.96 \mathrm{~mm}$; Natsume Seisakusho Co. LTD., Tokyo, Japan) for blood sampling and i.v. injection, respectively.

\section{Drug administration}

The rats were divided into six groups ( $n=6$, each): an oral control group $\left(0.5 \mathrm{mg} \cdot \mathrm{kg}^{-1}\right.$ of repaglinide dissolved in distilled water, $1.0 \mathrm{ml} \cdot \mathrm{kg}^{-1}$ ) without or with 0.3 and $1.0 \mathrm{mg} \cdot \mathrm{kg}^{-1}$ of nisoldipine (mixed in distilled water, $3.0 \mathrm{ml} \cdot \mathrm{kg}^{-1}$ ), and an IV control group $\left(0.2 \mathrm{mg} \cdot \mathrm{kg}^{-1}\right.$ of repaglinide, dissolved in $0.9 \%$ $\mathrm{NaCl}$ solution, $1.5 \mathrm{ml} \cdot \mathrm{kg}^{-1}$ ) without or with 0.3 and $1.0 \mathrm{mg}$. $\mathrm{kg}^{-1}$ of nisoldipine (mixed in distilled water, $3.0 \mathrm{ml} \cdot \mathrm{kg}^{-1}$ ). Oral repaglinide was administered intragastrically using a feeding tube, and nisoldipine was administered in the same manner $30 \mathrm{~min}$ prior to the oral administration of repaglinide. Repaglinide for IV administration was injected through the femoral vein within $0.5 \mathrm{~min}$. A $0.4-\mathrm{ml}$ aliquot of blood was collected into heparinized tubes from the femoral artery at $0.25,0.5$, $0.75,1,2,4,6$, and $10 \mathrm{~h}$ after repaglinide oral administration and at $0,0.1,0.25,0.5,1,2,6$, and $10 \mathrm{~h}$ after repaglinide IV administration. The blood samples were centrifuged at 13000 rpm for $3 \mathrm{~min}$, and the plasma samples were stored at $-40^{\circ} \mathrm{C}$ until HPLC analysis.

\section{HPLC analysis}

Plasma concentration of repaglinide was determined by HPLC as reported by Ruzilawati et al. (2007) with a slight modification. Briefly, a $50-\mu \mathrm{l}$ aliquot of $1 \mu \mathrm{g} \cdot \mathrm{ml}^{-1}$ indomethacin, as an internal standard, and a $0.2-\mathrm{ml}$ aliquot of $0.1 \mathrm{~mol} \cdot \mathrm{I}^{-1}$ potassium dihydrogen orthophosphate (KH2PO4, $\mathrm{pH}$ 5.9) were mixed with a $0.2-\mathrm{ml}$ aliquot of the plasma sample. After the mixture was vortexed, $1 \mathrm{ml}$ of ethylacetate, $50 \mu$ of isoamylalcohol and $35 \mu \mathrm{l}$ of $1 \mathrm{M} \mathrm{NaOH}$ were added. The resulting mixture was then vortex-mixed for $10 \mathrm{~min}$ and centrifuged at 9000 rpm for $10 \mathrm{~min}$. After centrifugation, the ethylacetate phase was transferred into a clean test tube and evaporated under a gentle stream of nitrogen gas at $45^{\circ} \mathrm{C}$. The dried extract was reconstituted with $150 \mu \mathrm{l}$ of mobile phase, vortex-mixed and transferred to a clean autosampler vial. A $70-\mu$ l aliquot of the supernatant was injected into the HPLC system. Chromatographic separation was achieved using a $\mu$ Bondapak $^{\mathrm{TM}} \mathrm{C} 18$ column $(3.9 \times 300 \mathrm{~mm}$ i.d., $10 \mu \mathrm{m}$, Waters Co. $)$ attached to a $\mu$ Bondapak ${ }^{\mathrm{TM}} \mathrm{C} 18$ guard column $(3.9 \times 20 \mathrm{~mm}$ i.d., $10 \mu \mathrm{m}$, Waters Co.). The mobile phase consisted of $20 \mathrm{mM}$ dipotassium hydrogen phosphate ( $\mathrm{pH} 2.7$, adjusted with phosphoric acid)acetonitrile $(60: 40, \mathrm{v} / \mathrm{v})$. The flow-rate of the mobile phase was maintained at $1.0 \mathrm{ml} / \mathrm{min}$. Chromatography was performed at $30^{\circ} \mathrm{C}$ and regulated by an HPLC column temperature controller. The UV detector was operated at a wavelength of 244 $\mathrm{nm}$. Repaglinide and indomethacin were eluted with retention times at 7.4 and $8.4 \mathrm{~min}$, respectively. The lower limit of quantification for repaglinide in rat plasma was $20 \mathrm{ng} \cdot \mathrm{ml}^{-1}$. The intra- and inter-day coefficients of variation of repaglinide were below 12.1 and $11.5 \%$, respectively.

\section{CYP inhibition assay}

The assays of inhibition of human CYP3A4 enzyme activity were performed in a multiwell plate using CYP inhibition assay kit (GENTEST, Woburn, MA) as described previously (Crespi et al., 1997). Briefly, human CYP enzymes were obtained from baculovirus-infected insect cells. CYP substrate (7-BFC for CYP3A4) was incubated with or without nisordipine in the enzyme/substrate buffer consisting of 1 pmol of P450 enzyme and a NADPH generating system (1.3 mM NADP, $3.54 \mathrm{mM}$ glucose 6-phosphate, $0.4 \mathrm{U} \cdot \mathrm{ml}^{-1}$ glucose 6-phosphate dehydrogenase and $3.3 \mathrm{mM} \mathrm{MgCl}_{2}$ ) in a potassium phosphate buffer ( $\mathrm{pH}$ 7.4). Reactions were terminated by adding stop solution after 45-min incubation. Metabolite concentrations were measured by spectrofluorometer (Molecular Devices, Sunnyvale, CA) at an excitation wavelength of $409 \mathrm{~nm}$ and an emission wavelength of $530 \mathrm{~nm}$. Positive control ( $1 \mu \mathrm{M}$ ketoconazole for CYP3A4) was run on the same plate and produced $99 \%$ inhibition. All experiments were performed in duplicate and results are expressed as the percent of inhibition.

\section{Rhodamine-123 retention assay}

The procedures used for the Rho- 123 retention assay were similar to a previously reported method (Han et al., 2008). 

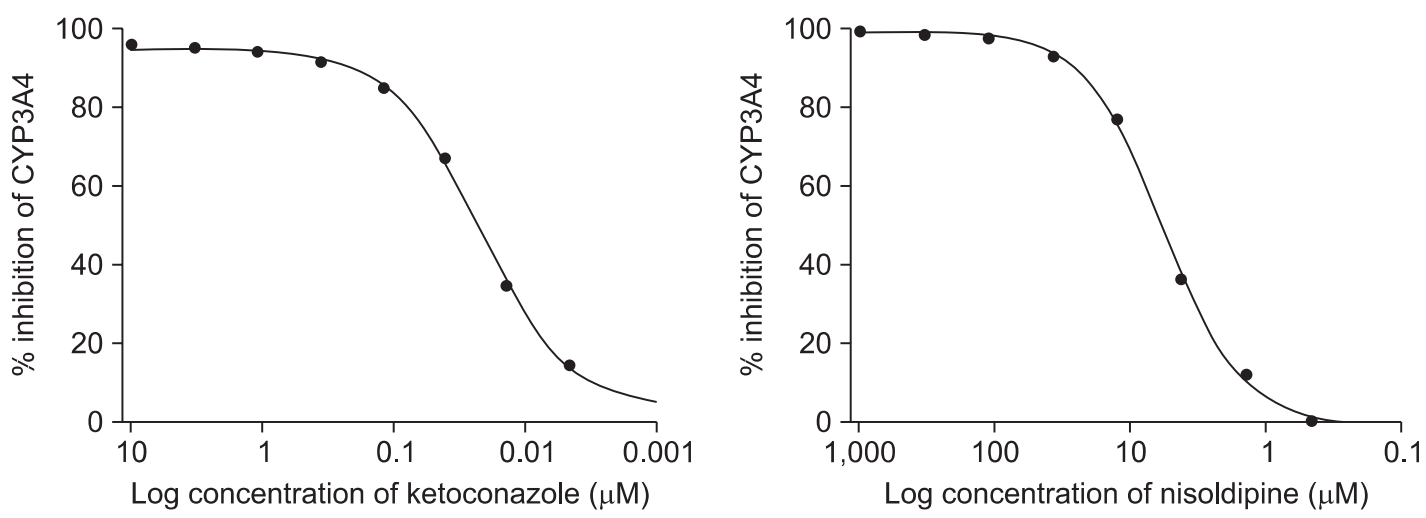

Fig. 1. Inhibitory effect of ketoconazole and nisoldipine on CYP3A4 activity. The experiment was done in duplicate and the result is expressed as the percent of inhibition.

MCF-7/ADR cells were seeded in 24-well plates at dencity of $10^{5}$ cells. At $80 \%$ confluence, the cells were incubated in fetal bovine serum (FBS) free Dulbecco's modified Eagle's medium (DMEM) for $18 \mathrm{~h}$. The culture medium was changed to Hanks' balanced salt solution and the cells were incubated at $37^{\circ} \mathrm{C}$ for $30 \mathrm{~min}$. After incubation of the cells with $20 \mu \mathrm{M}$ rhodamine-123 in the presence or absence of nisoldipine (50 and $100 \mu \mathrm{M})$ or verapamil $(100 \mu \mathrm{M})$ for $90 \mathrm{~min}$, the medium was completely removed. The cells were then washed three times with icecold phosphate buffer ( $\mathrm{pH} 7.0)$ and lysed in EBC lysis buffer. Rhodamine-123 fluorescence in the cell lysates was measured using excitation and emission wavelengths of 480 and $540 \mathrm{~nm}$, respectively. Fluorescence values were normalized to the total protein content of each sample and are presented as the ratio to control. Verapamil $(100 \mu \mathrm{M})$ was used as a positive control.

\section{Pharmacokinetic analysis 5}

The plasma concentration data were analyzed by the noncompartmental method using Thermo Kinetica Software Version 5.0 (Thermo Fisher Scientific Inc., Miami, OK, USA). The elimination rate constant $\left(\mathrm{K}_{\mathrm{el}}\right)$ was calculated by log-linear regression of repaglinide concentration during the elimination phase. The terminal half-life $\left(t_{1 / 2}\right)$ was calculated by $0.693 / \mathrm{K}_{\mathrm{el}}$. The peak plasma concentration $\left(\mathrm{C}_{\max }\right)$ and time to reach peak plasma concentration $\left(T_{\max }\right)$ of repaglinide in plasma were obtained by visual inspection of the data from the concentrationtime curve. The area under the plasma concentration-time curve $\left(A \cup C_{0-t}\right)$ from time zero to the time of last measured concentration $\left(\mathrm{C}_{\text {last }}\right)$ was calculated by the linear trapezoidal rule. The AUC from zero to infinite $\left(A \cup C_{0-\infty}\right)$ was obtained by the addition of $\mathrm{AUC}_{0-\mathrm{t}}$ and the extrapolated area determined by $\mathrm{C}_{\text {last }} / \mathrm{K}_{\mathrm{el}}$. Total body clearance (CL/F) was calculated by Dose/ AUC. The absolute bioavailability (A.B.) was calculated by $A \cup C_{\text {oral }} / A \cup C_{\text {iv }} \times$ Dose $_{\text {iv }} /$ Dose $_{\text {oral }} \times 100 \%$, and the relative bioavailability (R.B.) was calculated by $A \cup C_{\text {with nisoldipine }} / A U_{\text {control }} \times 100 \%$.

\section{Statistical analysis}

Statistical analysis was conducted using one-way ANOVA followed by a posteriori testing with the Dunnett correction. Differences were considered to be significant at $p<0.05$. All mean values are presented with their standard deviation (Mean \pm S.D.).

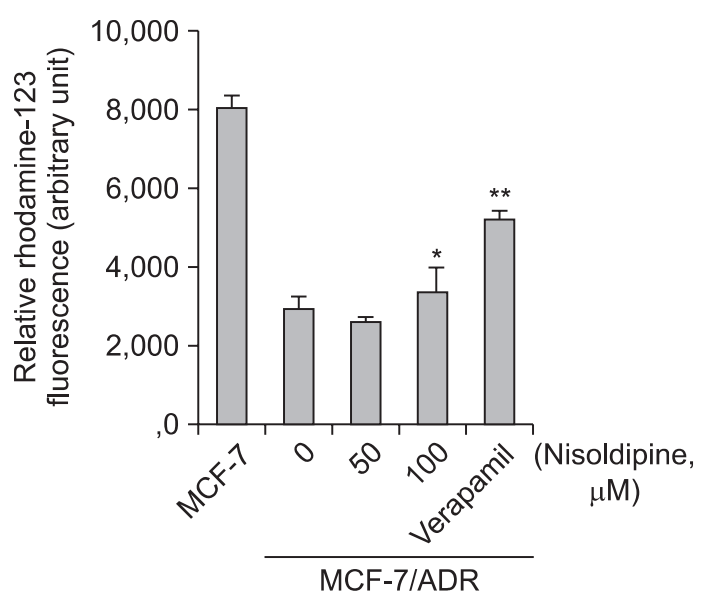

Fig. 2. Rhodamine-123 retention. MCF-7/ADR cells were preincubated with nisoldipine for $30 \mathrm{~min}$ after incubation of MCF-7/ADR cells with $20 \mu \mathrm{M}$ R-123 for $90 \mathrm{~min}$. Data represents mean $\pm \mathrm{SD}$ of 6 separate samples (significant versus the control MCF-7 cells, $\left.{ }^{*} p<0.05,{ }^{* *} p<0.01\right)$.

\section{RESULTS}

\section{Inhibition of CYP3A4}

The inhibitory effect of nisoldipine on CYP3A4 activity is shown in Fig. 1. Nisoldipine inhibited CYP3A4 activity in a concentration-dependent manner. Ketoconazole and nisoldipine strongly inhibited CYP3A4 with an $\mathrm{IC}_{50}$ value of 0.03 and $5.5 \mu \mathrm{M}$.

\section{Rhodamine- 123 retention assay}

As shown in Fig. 2, accumulation of rhodamine-123, a $\mathrm{P}$-gp substrate, was raised in MCF-7/ADR cells overexpressing P-gp compared to that in MCF-7 cells lacking P-gp. The concurrent use of nisoldipine enhanced the cellular uptake of rhodamine 123 in a concentration-dependent manner and the uptake was significantly $(p<0.01)$ increased at concentrations ranging at $100 \mu \mathrm{M}$. This result suggests that nisoldipine significantly inhibits P-gp activity. 


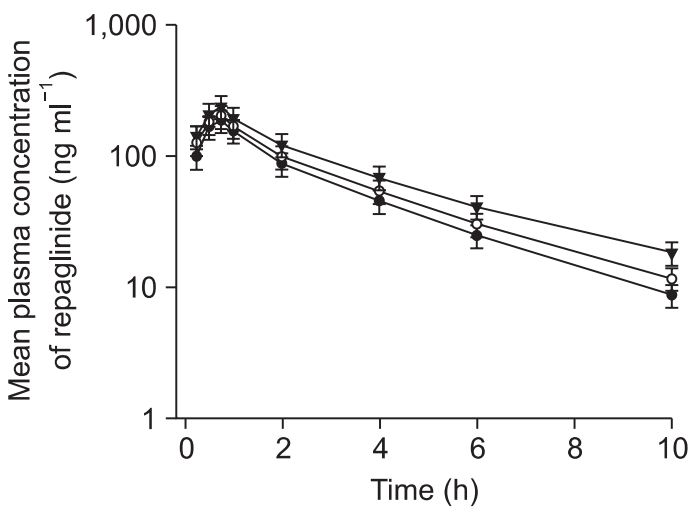

Fig. 3. Mean plasma concentration-time profiles of repaglinide after oral $\left(0.5 \mathrm{mg} \cdot \mathrm{kg}^{-1}\right)$ administration of repaglinide to rats in the presence or absence of nisoldipine $\left(0.3\right.$ and $\left.1.0 \mathrm{mg} \cdot \mathrm{kg}^{-1}\right)(\mathrm{n}=6$, each). Bars represent the standard deviation; (0) Oral administration of repaglinide (control); $(\bigcirc)$ with $0.3 \mathrm{mg} \cdot \mathrm{kg}^{-1}$ nisoldipine; $(\boldsymbol{\nabla})$ with $1.0 \mathrm{mg} \cdot \mathrm{kg}^{-1}$ nisoldipine.

\section{Effect of nisoldipine on the pharmacokinetics of oral repaglinide}

Mean arterial plasma concentration-time profiles of repaglinide following oral administration of repaglinide $(0.5 \mathrm{mg}$. $\left.\mathrm{kg}^{-1}\right)$ to rats in the presence or absence of nisoldipine ( 0.3 and $1.0 \mathrm{mg} \cdot \mathrm{kg}^{-1}$ ) are shown in Fig. 3; the corresponding pharmacokinetic parameters are shown in Table 1. Nisoldipine significantly altered the pharmacokinetic parameters of repaglinide. Compared to the control group (given oral repaglinide alone), nisoldipine significantly increased the area under the plasma concentration-time curve $\left(\mathrm{AUC}_{0-\infty}, p<0.01 \mathrm{at} 1.0 \mathrm{mg} \cdot \mathrm{kg}^{-1}\right)$ and the peak plasma concentration $\left(C_{\max }, p<0.05\right.$ at $\left.1.0 \mathrm{mg} \cdot \mathrm{kg}^{-1}\right)$ of repaglinide by $46.9 \%$ and $24.9 \%$, respectively. The terminal half-life $\left(t_{1 / 2}\right)$ was significantly increased by nisoldipine. Nisoldipine also increased the absolute bioavailability (A.B.) of repaglinide by $49.4 \%$ ( $p<0.01 \mathrm{for} 1.0 \mathrm{mg} \cdot \mathrm{kg}^{-1}$ ) compared to the oral control group (33.6\%), and the relative bioavailability (R.B.) of repaglinide by 1.16 - to 1.47 -fold. There were no significant differences in the time to reach peak plasma concentration $\left(T_{\max }\right)$ of repaglinide in the presence of nisoldipine.

\section{Effect of nisoldipine on the pharmacokinetics of intrave- nous repaglinide}

Mean plasma concentration-time profiles of repaglinide after the intravenous administration of repaglinide $(0.2 \mathrm{mg}$. $\left.\mathrm{kg}^{-1}\right)$ to rats in the presence or absence of nisoldipine $(0.3$ and $1.0 \mathrm{mg} \cdot \mathrm{kg}^{-1}$ ) are shown in Fig. 4 , while the correlated pharmacokinetic parameters are shown in Table 2. Compared to the control group, nisoldipine at $1.0 \mathrm{mg} \cdot \mathrm{kg}^{-1}$ significantly $(p<0.05)$ increased the $A_{U C} C_{0-\infty}(26.4 \%)$ of repaglinide. The $\mathrm{CL}_{t}$ values of repaglinide tended to decrease, but was not statistically significant. The $t_{1 / 2}$ of repaglinide was also increased, but this increase was not significant.

Accordingly, while there was no significant change in the intravenous pharmacokinetics of repaglinide, the enhanced oral bioavailability in the presence of nisoldipine could mainly be due to inhibition of P-gp in the small intestine and to inhibition of CYP3A subfamily in the small intestine and/or in liver by nisoldipine rather than reduction of renal elimination of repaglinide.
Table 1. Mean ( \pm S.D.) pharmacokinetic parameters of repaglinide after the oral administration of repaglinide $\left(0.5 \mathrm{mg} \cdot \mathrm{kg}^{-1}\right)$ to rats in the presence or absence of nisoldipine $\left(0.3\right.$ and $\left.1.0 \mathrm{mg} \cdot \mathrm{kg}^{-1}\right)(\mathrm{n}=6$, each).

\begin{tabular}{lccc}
\hline \multirow{2}{*}{ Parameter } & \multirow{2}{*}{$\begin{array}{c}\text { Repaglinide } \\
\text { (Control) }\end{array}$} & \multicolumn{2}{c}{ Nisoldipine } \\
\cline { 3 - 4 } & & $0.3 \mathrm{mg} \cdot \mathrm{kg}^{-1}$ & $1.0 \mathrm{mg} \cdot \mathrm{kg}^{-1}$ \\
\hline $\mathrm{AUC}_{0-\infty}\left(\mathrm{ng} \cdot \mathrm{h} \cdot \mathrm{ml}^{-1}\right)$ & $544 \pm 91$ & $631 \pm 113$ & $799 \pm 152^{\mathrm{b}}$ \\
$\mathrm{C}_{\max }\left(\mathrm{ng} \cdot \mathrm{ml}^{-1}\right)$ & $185 \pm 31$ & $197 \pm 35$ & $231 \pm 41^{\mathrm{a}}$ \\
$\mathrm{T}_{\max }(\mathrm{h})$ & $0.67 \pm 0.13$ & $0.71 \pm 0.10$ & $0.79 \pm 0.10$ \\
$\mathrm{t}_{1 / 2}(\mathrm{~h})$ & $2.4 \pm 0.4$ & $2.7 \pm 0.5$ & $3.2 \pm 0.5^{\mathrm{a}}$ \\
A.B. $(\%)$ & $33.6 \pm 6.0$ & $39.0 \pm 7.4$ & $49.4 \pm 9.9^{\mathrm{b}}$ \\
R.B. $(\%)$ & 100 & 116 & 147 \\
\hline
\end{tabular}

${ }^{a} p<0.05,{ }^{b} p<0.01$, significant difference compared to control. $\mathrm{AUC}_{0-\infty}$ : area under the plasma concentration-time curve from 0 $h$ to infinity, $C_{\text {max }}$ : peak plasma concentration, $T_{\max }$ : time to reach $C_{\max }, t_{1 / 2}$ : terminal half-life, A.B.: absolute bioavailability, R.B.: relative bioavailability.

\section{DISCUSSION}

Type 2 diabetes mellitus is a common health problem associated with cardiovascular disease, with an increasing incidence worldwide (Gomes et al., 2009), and hypertension is an extremely common co-morbid condition in diabetes, affecting more than $50 \%$ of patients with diabetes mellitus (Marques et al., 2002). In recent years, clinical trials have demonstrated the effectiveness of aggressive treatment of hypertension in reducing macrovascular and microvascular diabetes complications. Thus, a target blood pressure goal of lower than $130 / 80 \mathrm{mmHg}$ is now recommended. It must be noted that many patients will require three or more drugs (Marques et al., 2002). Structures of nisoldipine including calcium antagonists of the dihydropyridine class, to achieve blood pressure control (American Diabetes Association, 2002).

The importance of first-pass metabolism for limiting systemic drug availability is well established; however, intestinal drug metabolism can further diminish systemic availability. Through functional enzyme activity studies and immunoblot analyses, CYP3A expression in mature enterocytes, located mainly in the villi tips, of jejunal mucosa was shown to be comparable to or even exceed the expression of CYP3A in hepatocytes (Watkins, 1992). Total CYP P450 content increased slightly proceeding from the duodenum to the jejunum and then decreased sharply to the ileum (Zhang et al., 1999). Using in situ hybridization with a probe specific for CYP3A4, McKinnon confirmed CYP3A expression throughout the entire small intestine, with highest levels in the proximal regions (McKinnonand and McManus, 1996). The most abundant CYP isoenzyme in the intestine is 3A4 (Tubic-Grozdanis et al., 2008).

Based on their broad overlap in substrate specificities as well as their co-localization in the small intestine, the primary site of absorption for orally administered drugs, CYP3A4 and P-gp have been recognized as a concerted barrier to drug absorption (Wacher et al., 2001; Cummins et al., 2002). CYP enzymes significantly contribute to the first-pass metabolism and the oral bioavailability of many drugs. Moreover, induction or inhibition of intestinal CYPs may be responsible for significant drug-drug interactions when one agent decreases or increases the bioavailability and absorption rate constant of 


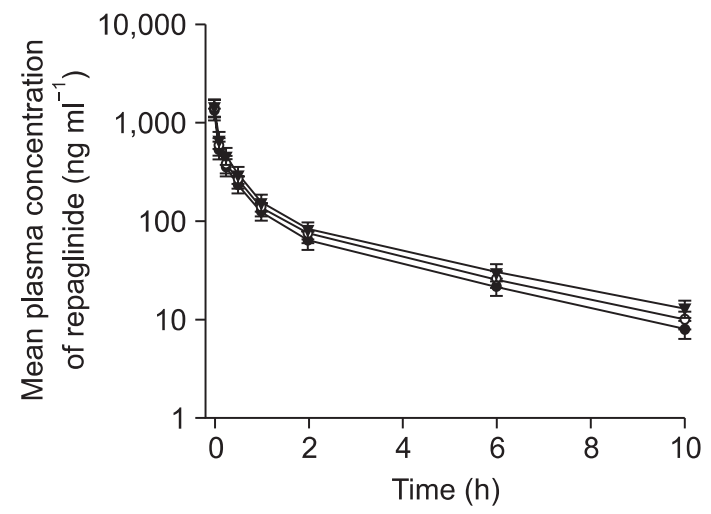

Fig. 4. Mean plasma concentration-time profiles of repaglinide after intravenous $\left(0.2 \mathrm{mg} \cdot \mathrm{kg}^{-1}\right)$ administration of repaglinide to rats in the presence or absence of nisoldipine $\left(0.3\right.$ and $\left.1.0 \mathrm{mg} \cdot \mathrm{kg}^{-1}\right)$ $(n=6$, each). Bars represent the standard deviation, $(0)$ Intravenous administration of repaglinide (control); $(\bigcirc)$ with $0.3 \mathrm{mg} \cdot \mathrm{kg}^{-1}$ nisoldipine; $(\boldsymbol{\nabla})$ with $1.0 \mathrm{mg} \cdot \mathrm{kg}^{-1}$ nisoldipine.

another drug administered concurrently (Kaminsky and Fasco, 1991). Therefore, dual inhibitors against both CYP3A4 and $\mathrm{P}$-gp should have a great impact on the bioavailability of many drugs where CYP3A4 metabolism as well as P-gp mediated efflux is the major barrier to the systemic availability. Considering that repaglinide is a substrate of both CYP3A4 and P-gp (Chang et al., 1984; Bidstrup et al., 2003), CYP3A4 and P-gp inhibitors might alter the bioavailability and pharmacokinetics of repaglinide. The inhibitory effect of nisoldipine against CYP3A4-mediated metabolism was confirmed through the use of recombinant CYP3A4 enzyme.

As shown in Fig. 1, nisoldipine inhibited CYP3A4 activity with an $\mathrm{IC}_{50}$ value of $5.5 \mu \mathrm{M}$. Furthermore, the cell-based assay using rhodamine-123 indicated that nisoldipine $(100 \mu \mathrm{M})$ significantly $(p<0.01)$ inhibited P-gp-mediated drug efflux (Fig. 2 ). Therefore, the pharmacokinetic characteristics of repaglinide were evaluated in the absence and presence of nisoldipine in rats. As CYP3A9 expressed in rat corresponds to the ortholog of CYP3A4 in human (Kelly et al., 1999), rat CYP3A2 is similar to human CYP3A4 (Guengerich et al., 1986; Bogaards et al., 2000). Human $3 A 4$ and rat $3 A 1$ have $73 \%$ of protein homology (Lewis, 1996). Rats were selected as an animal model in this study to evaluate the potential pharmacokinetic interactions mediated by CYP3A4, although there should be some-difference in enzyme activity between rat and human (Cao et al., 2006). Therefore, nisoldipine might increase absorption of repaglinide in the intestine through the inhibition of P-gp and CYP3A4.

As shown in Table 1, nisoldipine significantly $\left(1.0 \mathrm{mg} \cdot \mathrm{kg}^{-1}\right.$, $p<0.01)$ increased the $A \cup C_{0-\infty}$ of repaglinide. Nisoldipine also significantly $\left(1.0 \mathrm{mg} \cdot \mathrm{kg}^{-1}, p<0.01\right)$ increased the absolute bioavailability (A.B.) of repaglinide by $49.4 \%$ compared to the oral control group, and the relative bioavailability (R.B.) of repaglinide was increased by $1.16-$ to 1.47 -fold. These results are consistent with a report by Niemi et al. (2001) showing that clarithromycin, a CYP3A4 inhibitor, significantly increased the $\mathrm{AUC}_{0-\infty}$ and $\mathrm{C}_{\text {max }}$ of repaglinide. Niemi et al. (2003) reported that gemfibrozil significantly increased the $\mathrm{AUC}_{0-\infty}$ of repaglinide 8.1-fold, while Kajosaari et al. (2005) also reported that co-administration of repaglinide with the known P-gp inhibitor
Table 2. Mean ( \pm S.D.) pharmacokinetic parameters of repaglinide after the intravenous administration of repaglinide $\left(0.2 \mathrm{mg} \cdot \mathrm{kg}^{-1}\right)$ to rats in the presence or absence of nisoldipine $\left(0.3\right.$ and $\left.1.0 \mathrm{mg} \cdot \mathrm{kg}^{-1}\right)(\mathrm{n}=6$, each).

\begin{tabular}{lccc}
\hline \multirow{2}{*}{ Parameter } & \multirow{2}{*}{$\begin{array}{c}\text { Repaglinide } \\
\text { (Control) }\end{array}$} & \multicolumn{2}{c}{ Nisoldipine } \\
\cline { 3 - 4 } & & $0.3 \mathrm{mg} \cdot \mathrm{kg}^{-1}$ & $1.0 \mathrm{mg} \cdot \mathrm{kg}^{-1}$ \\
\hline $\mathrm{AUC}_{0-\infty}\left(\mathrm{ng} \cdot \mathrm{h} \cdot \mathrm{ml}^{-1}\right)$ & $647 \pm 98$ & $723 \pm 116$ & $818 \pm 175^{\mathrm{a}}$ \\
$\mathrm{t}_{1 / 2}(\mathrm{~h})$ & $2.5 \pm 0.6$ & $2.7 \pm 0.6$ & $3.0 \pm 0.7$ \\
$\mathrm{CL}_{\mathrm{t}}\left(\mathrm{ml} \cdot \mathrm{min}^{-1}\right)$ & $5.1 \pm 1.3$ & $4.5 \pm 1.0$ & $4.1 \pm 1.0$ \\
R.B. $(\%)$ & 100 & 112 & 126 \\
\hline
\end{tabular}

${ }^{a} p<0.05$, significant difference compared to control. $\mathrm{AUC}_{0-\infty}$ : area under the plasma concentration-time curve from $0 \mathrm{~h}$ to infinity, $\mathrm{t}_{1 / 2}$ : terminal half-life, $\mathrm{CL}_{\mathrm{t}}$ : total body clearance, R.B.: relative bioavailability.

cyclosporine A significantly increased the plasma concentration of repaglinide in humans.

After intravenous administration of repaglinide with nisoldipine, the $A \cup C_{0-\infty}$ of repaglinide was significantly increased by nisoldipine (Table 2 ). The $\mathrm{CL}_{t}$ values of repaglinide tend to decrease, but was not statistic significant. This suggests that the effects of oral nisoldipine on the inhibition of hepatic metabolism of repaglinide via CYP3A4 were almost negligible. In contrast to those of oral repaglinide, the pharmacokinetics of intravenous repaglinide were not affected by the concurrent use of nisoldipine. Accordingly, while there was no significant change in the pharmacokinetics of intravenous repaglinide, the enhanced oral bioavailability, may mainly be due to increased intestinal absorption via P-gp inhibition by nisoldipine rather than to reduced hepatic and renal elimination of repaglinide.

Nisoldipine significantly enhanced the oral bioavailability of repaglinide. The increase in the oral bioavailability of repaglinide might be mainly attributed to reduced first-pass metabolism of repaglinide via the inhibition of the CYP3A subfamily in the small intestine and/or in the liver and the inhibition of $\mathrm{P}$-gp in the intestine rather than to reduction of renal elimination of repaglinide by nisoldipine. Concomitant use of nisoldipine and repaglinide will require close monitoring of potential drug interaction for safe therapy of cardiovascular diseases. Furthermore, the clinical importance of these findings should be investigated in clinical trials.

\section{REFERENCES}

American Diabetes Association (2002) Treatment of hypertension in adults with diabetes. Diabetes Care 25, S71-S73.

Bauer, E., Beschke, K., Ebner, T. and Greischel, A. (1997) Biotransformation of [14C] repaglinide in human, cynomolgus monkey, dog, rabbit, rat and mouse. Diabetologia. 1, 326-332.

Bidstrup, T. B., Bjprnsdottir, I., Sidelmann, U. G., Thomsen, M. S. and Hansen, K. T. (2003) CYP2C8 and CYP3A4 are the principal enzymes involved in the human in vitro biotransformation of the insulin secretagogue repaglinide. Br. J. Clin. Pharmacol. 56, 305-314.

Bogaards, J. J., Bertrand, M., Jackson, P., Oudshoorn, M. J., Weaver, R. J., van Bladeren, P. J. and Walther, B. (2000) Determining the best animal model for human cytochrome P450 activities: a comparison of mouse, rat, rabbit, dog, micropig, monkey and man. $\mathrm{Xe}$ nobiotica. 30, 1131-1152.

Cao, X., Gibbs, S. T., Fang, L., Miller, H. A., Landowski, C. P., Shin, H. C., Lennernas, H., Zhong, Y., Amidon, G. L., Yu, L. X. and Sun, D. (2006) Why is it challenging to predict intestinal drug absorption 
and oral bioavailability in human using rat model. Pharm. Res. 23 , 1675-1686.

Chandler, M. H. H., Clifton, G. D., Lettieri, J. T., Mazzu, A. L., Allington, D. R., Thieneman, A. C., Foster, T. S. and Harrison, M. R. (1992) Multiple dose pharmacokinetics of four different doses of nisoldipine in hypertensive patients. J. Clin. Pharmacol. 32, 571-575.

Chang, C., Bahadduri, P. M., Polli, J. E., Swaan, P. W. and Ekins, S (2006) Rapid identification of P-glycoprotein substrates and inhibitors. Drug Metab. Dispos. 34, 1976-1984.

Crespi, C. L., Miller, V. P. and Penman, B. W. (1997) Microtiter plate assays for inhibition of human, drug-metabolizing cytochromes P450. Anal. Biochem. 248, 188-190.

Culy, C. R. and Jarvis, B. (2001) Repaglinide: a review of its therapeutic use in type 2 diabetes mellitus. Drugs. 61, 1625-1660.

Cummins, C. L., Jacobsen, W. and Benet, L. Z. (2002) Unmasking the dynamic interplay between intestinal P-glycoprotein and CYP3A4. J. Pharmacol. Exp. Ther. 300, 1036-1045.

El-Houssieny, B. M., Wahman, L. F. and Arafa, N. M. (2010) Bioavailability and biological activity of liquisolid compact formula of repaglinide and its effect on glucose tolerance in rabbits. Biosci. Trends. 4, 17-24.

Gomes, M. B., Giannella-Neto, D., Faria, M., Tambascia, M., Fonseca, R. M., Rea, R., Macedo, G., Modesto-Filho, J., Schmid, H., Bittencourt, A. V., Cavalcanti, S., Rassi, N., Pedrosa, H. and Dib, S. A. (2009) Estimating cardiovascular risk in patients with type 2 diabetes: a national multicenter study in Brazil. Diabetol. Metab. Syndr. 1, 22-28.

Guengerich, F. P., Brian, W. R., Iwasaki, M., Sari, M. A., Ba" a" rnhielm, C. and Berntsson, P. (1991) Oxidation of dihydropyridine calcium channel blockers and analogues by human liver cytochrome P-450 IIIA4. J. Med. Chem. 34,1838-1844.

Guengerich, F. P., Martin, M. V., Beaune, P. H., Kremers, P., Wolff, T. and Waxman, D. J. (1986) Characterization of rat and human liver microsomal cytochrome P-450 forms involved in nifedipine oxidation, a prototype for genetic polymorphism in oxidative drug metabolism. J. Biol. Chem. 261, 5051-5060.

Han, C. Y., Cho, K. B., Choi, H. S., Han, H. K. and Kang, K. W. (2008) Role of FoxO1 activation in MDR1 expression in adriamycin-resistant breast cancer cells. Carcinogenesis. 29, 1837-1844.

Hatorp, V., Won-Chin, H. and Strange, P. (1999) Repaglinide pharmacokinetic in healthy young adult and eldery subjects. Clin. Ther 21, 702-710.

Kajosaari, L. I., Niemi, M., Neuvonen, M., Laitila, J., Neuvonen, P. J. and Backman, J. T. (2005) Cyclosporine markedly raises the plasma concentrations of repaglinide. Clin. Pharmacol. Ther. 78,
388-399.

Kaminsky, L. S. and Fasco, M. J. (1991) Small intestinal cytochromes P450. Crit. Rev. Toxocol. 21, 407-422.

Kelly, P. A., Wang, H., Napoli, K. L., Kahan, B. D. and Strobel, H. W. (1999). Metabolism of cyclosporine by cytochromes P450 3A9 and 3A4. Eur. J. Drug Metab. Pharmacokinet. 24, 321-328.

Lewis, D. F. V. (1996) Cytochrome P450. Substrate specificity and metabolism. In: Cytochromes P450. Structure, Function, and Mechanism. Taylor \& Francis, Bistrol.122-123.

Marbury, T. M., Ruckle, J. L., Hatorp, V., Andersen, M. P., Nielsen, K. K., Huang, W. C. and Strange, P. (2000) Pharmacokinetic of repaglinide in subjects with renal impairment. Clin. Pharmacol. Ther. 67, 7-15.

Marques, M. P., Coelho, E. B., Dos Santos, N. A., Geleilete, T. J. and Lanchote, V. L. (2002) Dynamic and kinetic disposition of nisoldipine enantiomers in hypertensive patients presenting with type-2 diabetes mellitus. Eur. J. Clin. Pharmacol. 58, 607-614.

McKinnonand, R. and McManus, M. (1996) Localization of cytochromes P450 in human tissues: Implications for chemical toxicity. Pathology 28, 148-155.

Niemi, M., Backman, J. T., Neuvonen, M., and Neuvonen, P. J. (2003) Effects of gemfibrozil, itraconazole, and their combination on the pharmacokinetics and pharmacodynamics of repaglinide: potentially hazardous interaction between gemfibrozil and repaglinide. Diabetologia 46, 347-351.

Niemi, M., Neuvonen, P. J. and Kivistö, K. T. (2001) The cytochrome P4503A4 inhibitor clarithromycin increases the plasma concentrations and effects of repaglinide. Clin. Pharmacol. Ther. 70, 58-65.

Tubic-Grozdanis, M., Hilfinger, J. M., Amidon, G. L., Kim, J. S., Kijek, P., Staubach, P. and Langguth, P. (2008) Pharmacokinetics of the CYP 3 A substrate simvastatin following administration of delayed versus immediate release oral dosage forms. Pharm. Res. 25, 1591-1600.

van Harten, J., Burggraaf, J., Ligthart, G. J., van Brummelen, P. and Breimer, D. D. (1989) Single- and multiple-dose nisoldipine kinetics and effects in the young, the middle-aged, and the elderly. Clin. Pharmacol. Ther. 45, 600-607.

Wacher, V. J., Salphati, L. and Benet, L. Z. (2001) Active secretion and enterocytic drug metabolism barriers to drug absorption. Adv. Drug Deliv. Rev. 46, 89-102.

Watkins, P. B. (1992) Drug metabolism by cytochromes P450 in the liver and small bowel. Gastroenterol. Clin. North Am. 21, 511-526.

Zhang, Q., Dunbar, D., Ostrowska, A., Zeisloft, S., Yang, J. and Kaminsky, L. (1999) Characterization of human small intestinal cytochromes P-450. Drug Metab. Dispos. 27, 804-809. 